*Mestrando em Direito pela Escola Paulista de Direito E-mail: joaogarani@gmail.com

**Doutor e mestre em Direito peDoutora em Direito Constitucional pela Pontifícia Universidade Católica de São Paulo

Professora na Escola Paulista de Direito

E-mail: evelinedenardi@uol.com. br

\section{MEDIAÇÃO EM CARTÓRIOS NA ITÁLIA E NO BRASIL}

\section{NOTARY PUBLIC MEDIATION IN ITALY E BRAZIL}

\section{Joao Garani* Eveline Denardi**}

Como citar: GARANI, Joao; DENARDI, Eveline. Mediação em cartórios na Itália e no Brasil. Scientia luris, Londrina, v. 25, n. 3, p. 92-108, nov. 2021. DOI 10.5433/21788189.2021v25n3p92. ISSN: 2178-8189.

Resumo: Este artigo tem como objetivo evidenciar a contribuição que as serventias extrajudiciais podem prestar para o aumento da efetividade dos meios extrajudiciais de solução de controvérsias e, mais especificamente, da mediação. Analisa-se ainda a colaboração com o Poder Judiciário, na medida em que o cartório tem um natural inclinação para absorver atribuições, tradicionalmente prestadas judicialmente, mas que, por não envolverem lides, podem ser solucionadas administrativamente. E, ainda que haja conflitos, como é o caso da mediação, o interesse das partes na composição permite a solução extrajudicial. Para tanto foi realizada uma revisão bibliográfica sobre o tema. Foi feito ainda um estudo do instituto da mediação no direito italiano, bem como do serviço notarial naquele país, com objetivo de verificar as contribuições que ele pode dar ao direito brasileiro.

Palavras-chave: Medição. Cartório. Itália. Brasil.

\begin{abstract}
This article aims to highlight the contribution that extrajudicial services can provide to increase the effectiveness of extrajudicial means of dispute resolution and, more specifically, mediation. Collaboration with the Judiciary Branch is also analyzed, insofar as the notary's office has a natural inclination to absorb attributions, traditionally provided in court, but which, as they do not involve disputes, can be resolved administratively. And, even if there are conflicts, as in the case of mediation, the interest of the parties in the composition allows for an extrajudicial solution. Therefore, a bibliographical review on the subject was carried out. A study was also carried out on the institute of mediation in Italian law, as well as on the notarial service in that country, in order to verify the contributions it can make to Brazilian law.
\end{abstract}

Keywords: Mediation. Notary. Italy. Brazil. 


\section{INTRODUÇÃO}

As serventias extrajudiciais têm presença intensa na vida da população, e acompanham o indivíduo nos principais momentos da sua existência. Como se sabe, todos nascem, muitos se casam e todos morrem. É certo que, para o Estado, o nascimento jurídico do indivíduo só ocorre com o respectivo registro, ocasião na qual ele é elevado ao status de cidadão. Nessa linha, a primeira contribuição dos cartórios para o Poder Público é justamente disponibilizar esses dados, que irão orientar a execução das políticas públicas. Até agora, mencionou-se apenas uma das atribuições do registro civil de pessoas naturais que, por sua vez, é um dos 7 tipos de cartórios existentes no país, nos termos do artigo $5^{\circ}$ da Lei n. 8.935/1994, abaixo reproduzido:

Art. $5^{\circ}$ Os titulares de serviços notariais e de registro são os: I - tabeliães de notas; II tabeliães e oficiais de registro de contratos marítimos; III - tabeliães de protesto de títulos; IV - oficiais de registro de imóveis; $\mathrm{V}$ - oficiais de registro de títulos e documentos e civis das pessoas jurídicas; VI - oficiais de registro civis das pessoas naturais e de interdições e tutelas; VII - oficiais de registro de distribuição (BRASIL, 1994).

Quando consideradas as competências de todas essas especialidades, tem-se uma gama extensa de atribuições cuja função principal é conferir autenticidade, segurança, publicidade e eficácia aos atos jurídicos. Dessa forma, o presente estudo tem por finalidade demonstrar, por meio de da análise do direito notarial e registral, a contribuição que os cartórios podem dar para o instituto da mediação. Para tanto, buscou-se examinar a experiência italiana sobre o tema, cuja sistemática pode trazer inspiração para o modelo brasileiro.

Seguindo esta linha, pretende-se demonstrar ainda como e porque as serventias extrajudiciais possuem uma vocação espontânea para auxiliar o Poder Judiciário realizando os procedimentos "alternativos" de solução de conflitos, tendo como foco a prática da mediação. Para subsidiar o presente artigo, antes do ingresso diretamente no tema da mediação cartorial no Brasil, analisar-se-á 
inicialmente e, em linhas gerais, a experiência italiana da mediação em cartórios. Nesse país, desde 2005, há uma entidade notarial competente para formar, incentivar e regular a mediação notarial, e, desde 2010, uma lei vanguardista específica sobre mediação. Importa notar ainda que a União Europeia Europa tem realizado um grande esforço para incentivar a prática da mediação, criando uma série de normas e de orientações gerais sobre o tema.

Em seguida, traçou-se um panorama geral da atuação dos cartórios no Brasil, a fim de verificar se eles têm conseguido efetivamente colaborar na administração da justiça. Por fim, foi analisada especificamente a atuação dos cartórios nos procedimentos de mediação extrajudicial.

\section{REGRAS GERAIS DA UNIÃO EUROPEIA}

São inegáveis as semelhanças entre o regramento dos métodos extrajudiciais de solução de conflitos entre os países europeus, especialmente no que tange ao instituto da mediação. Isso pode ser entendido, inicialmente, pela natural semelhança étnica, cultural, histórica e jurídica entre esses povos. Uma breve análise histórica permite identificar que desde o período de Carlos Magno - com a expulsão dos mouros, saxões e bávaros - houve o afloramento do sentimento identitário comum europeu, com o enaltecimento das semelhanças dos povos do território.

Não é por outra razão que o Papa João Paulo II referiu-se ao Imperador Carolíngio como o Pai da Europa em seu discurso de agradecimento, por ocasião do recebimento do Prêmio Internacional Carlos Magno. Aliás, já naquela oportunidade, em 2004, o Papa defendeu a mediação de valores, unidade política e liberdades individuais na Europa (JOÃO PAULO II, 2004).

Sem dúvidas, foi esse sentimento comum dos habitantes da Europa que permitiu sucessivas integrações políticas e econômicas que culminaram na formação da União Europeia, em 1993, com a assinatura do Tratado de Maastricht e, posteriormente, em 1999, com a adoção da moeda única.

Desde o início do bloco, suas decisões mais sensíveis são tomadas pelo Conselho Europeu. Hoje oficial, o Conselho teve sua primeira reunião em 1961, em Paris, informalmente. Agora, como instituição permanente, é responsável por promover políticas crescentes de integração entre os países europeus. O órgão possui também a função de mediar conflitos entre os Estados-membros, sendo considerado a maior autoridade política da União Europeia.

Com o advento do Tratado de Lisboa de 2007, que alterou o tratado da União Europeia e instituiu a Comunidade Europeia, estabeleceu-se a cooperação judiciária em matéria civil, assentada no princípio do reconhecimento mútuo das decisões judiciais e extrajudiciais, cujo objetivo é adotar medidas de aproximação das disposições legislativas dos Estados-membros.

O artigo 65 do referido diploma estabelece uma série de postulados de caráter integrativo, como a possibilidade de citação e notificação transfronteiriça dos atos judiciais e extrajudiciais e a busca pela compatibilização de normas regionais no que tange ao conflito de leis e de jurisdição. O Tratado igualmente se preocupou com o auxílio dos países para a obtenção de meios de prova, o acesso efetivo à justiça, além de eliminar barreiras à tramitação dos processos cíveis, promovendo, se necessário, a compatibilização da legislação processual civil dos Estados-membros. 
Há ainda a preocupação com a formação dos magistrados, funcionários e agentes de justiça. Mas o ponto que mais interessa a este artigo é justamente a previsão expressa no acordo da busca do desenvolvimento de métodos alternativos de resolução dos litígios. Importa notar que já em 1999, o Conselho, em uma de suas reuniões, solicitou aos países que criassem procedimentos extrajudiciais. Tal previsão foi efetivada 4 anos mais tarte pela Diretiva n. 52/2008, do Conselho da União Europeia, trazendo orientações para a implementação da mediação em matéria civil e comercial.

A principal norma regente dos procedimentos de mediação na Europa é a Diretiva n. 52/2008 editada pelo Parlamento Europeu e pelo Conselho da União Europeia. Trata-se de uma norma composta de orientações gerais que buscam a um só tempo estimular e uniformizar a adoção da mediação pelos Estados-membros.

Em linhas gerais, a diretiva traz os seguintes princípios: primeiro, a mediação deve ser pautada pela voluntariedade, salvo obrigatoriedade definida pelo Estado, mas sempre assegurando o acesso à justiça. O procedimento igualmente deve pautar-se pela informalidade e pela liberdade, para que as partes possam organizar o procedimento. Em regra, não deve haver a imposição rígida de prazos, embora os tribunais possam estipular prazos máximos. Também deve ser possível aos juízes e tribunais recomendarem diretamente a mediação pelas partes.

A diretiva também se preocupa com a boa formação dos mediadores para que os procedimentos ganhem a confiança das partes e tenham efetividade. Nesse sentido é o artigo 4 Garantir a qualidade da mediação:

1. Os Estados-Membros devem incentivar, por todos os meios que considerem adequados, o desenvolvimento e a adesão a códigos voluntários de conduta pelos mediadores e organismos que prestem serviços de mediação, bem como outros mecanismos eficazes de controlo da qualidade da prestação de serviços de mediação. 2. Os Estados-Membros devem incentivar a formação inicial e contínua dos mediadores, a fim de garantir que a mediação seja conduzida de modo eficaz, imparcial e competente relativamente às partes (ESTRASBURGO, 2008, art. 4).

A esse respeito, ainda em 2002, a convite do Conselho de Ministros da Justiça, a Comissão Europeia apresentou um Livro Verde para tratar dos meios "alternativos" de resolução de litígios (excluída arbitragem).

Como consequência, surgiram dois documentos. O primeiro deles foi a Diretiva n. 52/2008 e, o segundo, o Código Europeu de Conduta para Mediadores, formalmente publicado em julho de 2004. O Código é de observância facultativa pelos mediadores individuais e pelos órgãos de mediação - é certo que a adesão ao Código não afasta a incidência das normas dos países do bloco.

$\mathrm{O}$ documento dispõe que os mediadores frequentem um curso de mediação adequado e realizem estudos continuados visando aperfeiçoar suas aptidões e a qualidade das mediações. Também é dever do mediador aderir ao Código, informar às partes a respeito de suas qualificações profissionais e recusar mediar conflitos que fujam da sua capacidade e experiência. 
Um ponto interessante desse documento é a sua abordagem sobre a parcialidade. $\mathrm{O}$ mediador deve atuar de forma independente e neutra, mantendo absoluta imparcialidade. Assim, o mediador tem o dever de declarar-se impedido de iniciar ou prosseguir na mediação se houver qualquer situação que possa afetar sua independência. São exemplos citados no código de conduta, a existência de relação pessoal com uma das partes, interesse financeiro no resultado da mediação e ter o mediador prestado serviços a uma das partes.

O processo de mediação, segundo o código, deve correr de maneira que permita às partes conhecerem todo o seu desenvolvimento, além da função do mediador. É seu papel assegurar que as partes conheçam e concordem com os termos do procedimento, incluindo o dever de todos quanto à confidencialidade.

Há ainda a orientação para o mediador formalizar o acordo quando solicitado pelas partes. Entretanto, é de bom alvitre que o acordo seja sempre documentado. Isso garante a produção de uma prova pré-constituída do acerto, o que, em caso de descumprimento, irá dispensar a parte prejudicada de um demorado procedimento probatório, que certamente envolveria a necessidade de oitiva de testemunhas em audiência, reunião de documentos do procedimento e outras providências, evitáveis com a documentação do termo.

Finalizando a questão deontológica da mediação europeia, o estatuto que orienta a conduta dos mediadores se preocupou com a isonomia da mediação. Isso porque a condução dos trabalhos deve considerar as peculiaridades do caso concreto, inclusive eventuais desigualdades ou ilegalidades, podendo, por exemplo, ouvir as partes separadamente. Há também que se ter em mente sempre a necessidade de uma rápida resolução do conflito.

De um modo geral, é possível afirmar que a Diretiva n. 52/2008 teve uma boa aceitação entre os países do bloco. Tal foi a conclusão do Parlamento Europeu, formalizada por meio de resolução em 2017, P8TA 20170321 (ESTRASBURGO, 2017).

Entre as principais constatações da entidade está o fato de que países como Croácia, Estônia, Grécia, Hungria, Irlanda, Itália, Lituânia, Países-Baixos, Polônia, Portugal, Eslováquia e Espanha atualizaram e revisaram suas legislações internas para adequá-las à diretiva da União Europeia. Além disso, em todos os países há a possibilidade de o Poder Judiciário ser o indutor da mediação entre as partes. Em alguns países, a passagem pela mediação é obrigatória. Em muitos locais, os advogados são obrigados a informar seus clientes da possibilidade de buscar a mediação - o fato deverá constar das petições.

Alguns Estados-membros oferecem incentivos financeiros para que os litigantes optem pela mediação, seja reduzindo custos, seja aplicando sanções por recusa injustificada em considerar a composição. De modo geral, os resultados que a aplicação da diretiva nos países atingiu foi considerada bastante positiva, demonstrando que a mediação gerou a resolução de litígios de forma econômica, mais célere e, de certa forma, personalizada às necessidades das partes.

A respeito do Código de Conduta Europeu para Mediadores, tratado acima, o Conselho afirmou que se trata de um instrumento importante para assegurar a qualidade da mediação, e observou que é diretamente utilizado como base para códigos nacionais. Outra recomendação 
acatada em grande parte pelos países é a necessidade de frequentar um curso de formação de mediadores.

Também foi comemorada a providência de se desenvolver o Portal Europeu da Justiça, plataforma online oficial criada para possibilitar o acesso a dados dos sistemas de justiça dos países do bloco. Nele há uma área dedicada à mediação internacional entre os Estados-membros, com informações sobre os estágios da legislação sobre mediação em cada país. Providência fundamental já que são cada vez mais frequentes as relações que ultrapassam as fronteiras do Estado, como a formação de uniões de cidadãos de diferentes nacionalidades (URSO, 2012).

Segundo o Parlamento, considerando que a mediação e os demais métodos extrajudiciais de resolução de conflitos são facultativos, é indispensável aos Estados-membros a adoção de medidas para garantir que os acordos gozem de exequibilidade célere e econômica, respeitada a lei interna e comunitária.

Nesse sentido, houve preocupação com a necessidade de homologação dos acordos de mediação por autoridade pública, regra presente na maioria dos países. Isso porque tal providência, embora salutar para a segurança, pode acarretar incremento dos custos do procedimento. Importante salientar que no caso do acordo celebrado por um mediador notarial, o respectivo instrumento será dotado de fé pública na origem, o que dispensaria a intervenção de outro órgão público.

Outra questão constatada foi a dificuldade em se obter os dados sobre a mediação em todos os países, como, por exemplo, estatísticas de duração, custos e êxito. Essas informações devem ser buscadas pela Rede Judiciária Europeia, para uma análise mais precisa dos resultados da Diretiva 52.

Por fim, a resolução apresentou suas recomendações aos Estados-membros, que devem prosseguir incentivando a adoção da mediação, especialmente por meio de campanhas de informação, e da busca por uma maior integração entre os profissionais do direito nessa seara. Segundo o Parlamento, há também a necessidade de a Comissão criar normas gerais de mediação com a aplicação em toda comunidade, como forma de uniformizar minimamente a matéria. $\mathrm{Na}$ mesma linha, deve-se criar registros nacionais dos processos de mediação, o que permitiria aos mediadores consultas visando o seu aprimoramento. De modo geral, a resolução demonstrou que o Parlamento Europeu tem a mediação em alta conta e preocupa-se com a sua plena implementação em toda a Comunidade Europeia.

\section{MEDIAÇÃO NA ITÁLIA}

Pelas razões demonstradas acima, há grande semelhança no tratamento dado à mediação entre os países europeus. Assim, optamos por analisar mais detidamente o modelo italiano, campeão em número de mediações entre os países da Europa, para verificar se ele pode contribuir com o modelo nacional, sempre tendo por foco a mediação notarial.

A base legal que respalda a mediação entre os italianos é o Decreto Legislativo n. 28/2010 
(ALTALEX, 2020). O texto autoriza que quaisquer entes públicos ou privados, que tenham garantia de seriedade e eficiência, possam habilitar-se como órgãos mediação. Para tanto, devem obter registro e seguir as regras do Ministério da Justiça. Assim, ao contrário do Brasil (BRASIL, 2015), a função não é livre e só pode ser exercida por profissionais registrados do Ministério da Justiça, direta ou indiretamente (profissionais vinculados a órgão de mediação autorizado).

Algumas categorias, entretanto, receberam um tratamento menos rigoroso. Os conselhos de advogados, por exemplo, podem instituir um órgão de mediação dentro de cada tribunal. Nesse caso, seu registro é facilitado e ocorre mediante simples solicitação.

De forma semelhante, as câmaras de comércio, indústria, artesanato e agricultura, que exercem a mediação desde muito antes da lei, também são registradas mediante simples solicitação. A Lei n. 580/1993 já reconhecia às câmaras a atribuição para o exercício da arbitragem e da conciliação (ITÁLIA, 1993).

O direito italiano define a mediação como a atividade realizada por terceiro imparcial com o objetivo de auxiliar dois ou mais sujeitos na busca de um acordo amigável para a solução de uma controvérsia, ou com a formulação de uma proposta de resolução da mesma. Como o mediador é a pessoa que, individual ou coletivamente, realiza a mediação, permanece, em qualquer caso, privado do poder de fazer julgamentos ou decisões vinculativas para os destinatários do próprio serviço. Interessante notar que não há distinção entre a figura do mediador e do conciliador. A lei chama de conciliação a própria solução do conflito alcançada pela mediação, ou seja, o acordo.

Um ponto interessante na lei de mediação é a competência territorial. Novamente aqui, o direito estrangeiro afasta-se do nosso. De acordo com o artigo $4^{\circ}$ do Decreto Legislativo $n$. 28, o pedido de mediação deve ser apresentado a um mediador da localidade do foro que seria o competente para a propositura de eventual ação sobre a causa "La domanda di mediazione relativa alle controversie di cui all'articolo 2 è presentata mediante deposito di un'istanza presso un organismo nel luogo del giudice territorialmente competente per la controversia ${ }^{1 "}$ (ALTALEX, 2020, art. 4).

Quanto à obrigatoriedade, o direito italiano se afasta do brasileiro novamente. Isso porque, prevalece a orientação geral da diretiva europeia que indica que a mediação deve ser facultativa. Entretanto, a Itália (e outros países do bloco), determina a obrigatoriedade do procedimento de mediação em algumas matérias. Assim, a comprovação, nos autos, da tentativa frustrada de composição é condição de procedibilidade de determinadas ações.

$\mathrm{O}$ artigo $5^{\circ}$ do decreto determina que aqueles que pretendam ajuizar uma ação relativa a questões como condomínio, direitos reais, divisão, sucessões hereditárias, acordos de família, locação, comodato, arrendamento de empresas, ressarcimento por danos de veículos, responsabilidade médica, difamação, contratos de seguro, bancários e financeiros devem previamente tentar a mediação.

O juiz pode inclusive, ao receber a apelação, remeter as partes à mediação. Para tanto, o juiz deve avaliar a natureza da causa, o estado da instrução e o comportamento das partes. Nesse 1 O pedido de mediação relativo aos litígios referidos no artigo $2 .^{\circ}$ é apresentado através da apresentação de um pedido a um órgão em substituição do juiz territorialmente competente para o litígio (Tradução nossa). 
caso, a tentativa de mediação é condição de procedibilidade do recurso.

Naturalmente que a regra da obrigatoriedade deve ser executada de forma razoável. Devese cuidar para que o ambiente de mediação não seja hostil a qualquer das partes, sobretudo quando se tratar de relações desiguais. Além disso, o Professor da Universidade de Florença, Vicenzo Vigoriti (2009, p. 70), demonstra ainda preocupação com o local onde as tentativas de mediação devem ocorrer, especialmente em se tratando de relações transfronteiriças, para que não haja abusos contra a parte mais vulnerável.

Em 2012, a regra da obrigatoriedade da mediação foi declarada inconstitucional pelo Tribunal Constitucional. A Corte entendeu que obrigar as partes à mediação configura abuso de poder do Estado. Contudo, já em 2013, foi publicado o Decreto Legislativo n. 69 que voltou a prever a obrigatoriedade da mediação, alterando a redação do artigo $5^{\circ}$ do Decreto 28 . Porém, dessa vez, as partes podem invocar a cláusula opt-out.

O fato é que, somente em 2017, a Itália promoveu 20.965 acordos de medição. O próprio parlamento Europeu, na reunião realizada em 09/12/2017, afirmou que o país realiza 6 vezes mais mediações que a média dos demais países europeus. Em 2018, a taxa de sucesso de procedimentos de mediação que continuaram após a primeira audiência foi de 45\% (AUTOR?, ano?).

Outro fato curioso diz respeito à mediação induzida judicialmente. Inicialmente, os juízes não deram maior atenção ao instituto. Em 2015, apenas 2\% dos procedimentos de mediação começavam por iniciativa dos magistrados. Porém, com os resultados positivos aparecendo, esse número foi aumentando rapidamente e, em 2017 e 2018, passou a marca de 15\% (MATTUCCI, 2019).

A lei italiana preocupou-se também com a celeridade do procedimento, fixando prazo máximo de três meses para a duração da mediação. Essa providência deveria ser considerada por legisladores de outros países, já que uma das vantagens da mediação sobre o processo judicial mais invocadas é justamente a sua celeridade.

Atualmente, com a crise global da Covid-19, a Itália recorreu às novas tecnologias para mitigar os efeitos da pandemia. Em 17 de março de 2020, foi publicado o Decreto Legislativo n. 18 dispondo de medidas para combater o coronavírus (SARRACENO, 2020).

$\mathrm{O}$ artigo 83 da referida norma trata de providências no âmbito judicial, como os casos de suspensão de prazos e limitações de acesso ao público. O item 20 do artigo determinou a suspensão dos procedimentos de mediação. Entretanto, o diploma legal trouxe a possibilidade do uso de meios eletrônicos, notadamente de videoconferência para a prática de atos no âmbito da administração pública e do Poder Judiciário.

Dessa forma, nada obsta que os procedimentos de mediação continuem se realizando de forma remota. O mediador pode, portanto, seguir formalizando os acordos firmados por via remota, e autenticando acordos realizados por e enviados a ele eletronicamente, caso seja um notário mediador (SARRACENO, 2020). 


\section{ATIVIDADE NOTARIAL NA ITALIA}

O sistema notarial italiano é um dos mais antigos e respeitados do mundo. Na região de Bologna, onde há alguns dos seus registros mais remotos, a atuação dos notários desenvolveuse concomitante e simbioticamente à Universidade de Bolonha, famosa por ser a primeira do mundo, fundada no século XI. Entre as atribuições do notário primitivo, estava a transcrição de textos legais e a elaboração de documentos privados. Mas foi no século seguinte que os tabeliães italianos conquistaram sua principal característica: a fé pública. Desde então, seus atos passaram a ser considerados válidos, independentemente da intervenção de qualquer outra autoridade (LA STORIA..., 2005).

Atualmente, a função é outorgada diretamente pelo Ministério da Justiça após um concurso público nacional de 4 fases, realizado na cidade de Roma. Entre outros requisitos, o candidato deve ser graduado em direito e apresentar conduta moral irrepreensível. A atividade é regulamentada pela Lei n. 89/1913.

O principal órgão da classe é o Conselho Nacional do Notariado. Trata-se de órgão político, representativo da categoria, composto por 20 notários eleitos por todos os tabeliães do país.

O Conselho criou, em 2005, o ADR Notariato, órgão responsável pela prática de Mediação e Arbitragem pelos cartórios. Obtendo o registro junto ao Ministério da Justiça, em 2007, o ADR Notariato também atua na formação de mediadores civis e comerciais. O órgão oferece um curso completo de formação de mediadores, voltado para os tabeliães, realizado em Roma com 58 horas de duração. O programa inclui o estudo das normas e jurisprudência nacionais e comunitárias, o procedimento da mediação, técnicas de gestão de conflitos, comunicação e negociação, além da função do mediador, princípios deontológicos e responsabilidades. Novamente nesse ponto aparece a influência da diretiva 58 da União Europeia e do Código de Conduta para Mediadores.

Os notários gozam de grande confiabilidade na Itália, seguem rígidos códigos de conduta e estão sujeitos à fiscalização contínua e a sanções graves. Tanto que, ao falar sobre o código de conduta de mediadores, Rosa Francaviglia toma como exemplo as regras de conduta aplicadas aos notários. Segundo a autora, o profissional que, de qualquer modo, comprometa com sua conduta, pública ou privada, a sua dignidade ou reputação, o decoro ou o prestígio da classe, inclusive como a redução ilegal de emolumentos e concorrência desleal, fica sujeito às penas de suspensão e destituição da função, nos termos do artigo 147 da lei notarial (FRANCAVIGLIA, 2009, p. 172).

Além da elevada reputação dos tabeliães junto à sociedade italiana, há outras vantagens no procedimento de mediação notarial. Como é sabido, este profissional do direito tem como função precípua - mas não a única - a formalização da vontade das partes. Assim, o notário poderá assessorar de forma equilibrada ambos os contendores, moldando o acordo de forma que não haja extrapolação dos limites legais, morais ou de ordem pública, garantindo que o ajuste seja formalmente perfeito e materialmente equânime.

Um outro benefício advindo da mediação notarial é a sua formalização. Nesse ponto é 
conveniente de forma resumida os modelos registrais imobiliários. No Brasil, impera o sistema de direitos, que consiste no registro do instrumento obrigacional (contrato privado ou escritura pública) para gerar o direito real sobre o imóvel. Dessa forma, há uma forte presunção, que pode ser relativa ou absoluta, a depender do caso, sobre o direito de propriedade. Na Europa, esse sistema é adotado na Alemanha e na Espanha. De outro lado, tem-se o sistema de documentos, adotado na Itália (Itália, Código Civil, art. 2.643) em Portugal (Portugal, Código do Registo Predial, art. $5^{\circ}$ ) e em boa parte da Europa. Nesse modelo, a transferência da propriedade ocorre pelo contrato particular. E o registro desse documento ou a sua transcrição notarial tem função probatória e de gerar oponibilidade contra terceiros.

Assim, fica claro o proveito do acordo celebrado perante o notário. Com a formalização notarial, especialmente se a avença encampar bens imóveis, as partes garantem a oponibilidade contra terceiros e, por conseguinte, uma maior segurança, facilitando inclusive a sua exequibilidade.

Ademais, a Itália, como outros países, exige para a validade de determinados acordos, o visto de uma autoridade pública. Aqui, a mediação notarial aparece novamente como opção conveniente, pois o acordo assinado pelo notário já nasce dotado de fé pública, dispensando a interveniência de outro agente público.

\section{PANORAMA DO SERVIÇO EXTRAJUDICIAL NO BRASIL}

Os serviços notariais e registrais do Brasil têm experimentado recentemente uma considerável ampliação de suas atribuições. A confiança demonstrada pela sociedade nesses profissionais e a necessidade de o Estado dar respostas mais efetivas às demandas judiciais e sociais são alguns dos fatores que estão por trás desse movimento.

O notário e o registrador são profissionais do direito que, após aprovação em rigoroso concurso público de provas e títulos, recebem do Estado, por intermédio do Poder Judiciário, a delegação da função pública da prática dos atos extrajudiciais. O cerne da função é a própria fé pública, na qual o profissional é investido sob responsabilidade. Nesse sentido, ilustrativas as palavras do Tabelião Reinaldo Velloso dos Santos (2012, p. ???):

A atribuição de fé pública aos atos praticados por tais agentes está diretamente relacionada ao acesso por concurso público, meio de verificação não só da capacidade intelectual como também de idoneidade moral; à rigorosa e contínua fiscalização por órgãos do Poder Público; e à previsão de responsabilidade nos âmbito civil, administrativo e penal.

No Brasil, desde 2018, os cartórios notariais e de registro têm autorização expressa para atuar promovendo mediações e conciliações extrajudiciais. A medida chega num momento em que a atividade extrajudicial vem recebendo crescentemente novas atribuições. São exemplos desse fenômeno o procedimento de alteração de nome e sexo no registro de nascimento diretamente 
em cartório, nos termos do provimento n. 73/2018 do CNJ. Alguns estados, inclusive, adotaram medidas adicionais delegando outras atividades para o serviço extrajudicial. É o caso do estado de São Paulo que, desde 2013, permite que cartas de sentença de processos judiciais sejam extraídas por tabeliães de notas.

Contudo, o diploma mais vanguardista nessa seara, é a Lei n. 13.484/2017 que criou os ofícios de cidadania. A lei autoriza os cartórios com a especialidade do registro civil das pessoas naturais a prestar serviços de expedição de documento de identificação pessoal, cadastro de pessoa física, passaporte, carteira de trabalho, entre outros. Para tanto, faz-se necessária a celebração de um convênio com órgãos públicos responsáveis por tais documentos.

Naturalmente que tantos avanços acabam por gerar algumas resistências pontuais, notadamente daqueles que ainda têm uma visão mais concentradora do Poder Judiciário. Não é por outra razão que a lei acima foi alvo de uma ação direta de inconstitucionalidade, a ADI n. 5855/ DF, ajuizada pelo Partido Republicano Brasileiro (PRB) (ADI 5855/DF, Rel. Ministro Relator Alexandre de Moraes) (BRASIL, 2019).

EMENTA: CONSTITUCIONAL. PROCESSO LEGISLATIVO. ORGANIZAÇÃO DOS SERVIÇOS AUXILIARES DO PODER JUDICIÁRIO. MP 776. CONVERSÃO NA LEI 13.484/2017. ART. 29, §§ $3^{\circ}$ E $4^{\circ}$, DA LEI DE REGISTROS PÚBLICOS. PROVIMENTO 66/2018 DA CORREGEDORIA NACIONAL DE JUSTIÇA. AUTORIZAÇÃO PARA CELEBRAÇÃO DE CONVÊNIOS POR ENTIDADES DE CLASSE DOS OFICIAIS DO REGISTRO CIVIL DAS PESSOAS NATURAIS. CONTROLE PRÉVIO PELAS CORREGEDORIAS DOS TRIBUNAIS DE JUSTIÇA. INCONSTITUCIONALIDADE PARCIAL.

1. O acréscimo dos parágrafos $3^{\circ}$ e $4^{\circ}$ ao art. 29 da Lei de Registros Públicos, por emenda à MP 776, não se qualifica como contrabando legislativo, na medida em que há correlação temática com o objeto da proposição original. 2. É válida a atribuição aos Ofícios de Registro Civil das Pessoas Naturais de prestação de outros serviços remunerados, conexos aos seus serviços típicos, mediante convênio devidamente homologado pelo Poder Judiciário local, em credenciamento ou em matrícula com órgãos públicos e entidades interessadas, podendo o referido convênio ser firmado pela Documento assinado digitalmente conforme MP $\mathrm{n}^{\circ} 2.200-2 / 2001$ de 24/08/2001. O documento pode ser acessado pelo endereço http://www.stf.jus.br/portal/autenticacao/autenticarDocumento. asp sob o código D476-8F89-77B3-1E17 e senha 5629-3F1B-D140-2D60 Supremo Tribunal Federal Inteiro Teor do Acórdão - Página 1 de 43 Ementa e Acórdão ADI 5855 / DF entidade de classe dos Registradores Civis das Pessoas Naturais de mesma abrangência territorial do órgão da entidade interessada. 3.

O exercício de serviços remunerados pelos Ofícios de Registro Civil das Pessoas Naturais, mediante celebração de convênios, depende de prévia homologação pelo Poder Judiciário, conforme o art. 96, II, alínea "b", e art. 236, § $\mathbf{1}^{\mathbf{0}}$, da CF. 4. Medida cautelar parcialmente confirmada e Ação Direta julgada parcialmente procedente para conferir interpretação conforme ao $\S 3^{\circ}$ do art. 29, declarar nulidade parcial com redução de texto da expressão "independe de homologação", constante do $\S 4^{\circ}$ do referido art. 29 da Lei 6.015/1973, na redação dada pela Lei 13.484/2017, e declarar a constitucionalidade do 
Provimento 66/2018 da Corregedoria Nacional do Conselho Nacional de Justiça (BRASIL, 2019, grifo nosso).

O Ministro Relator Alexandre de Moraes destacou a importância da ampliação dos serviços prestados pelos cartórios, desde que respeitada a pertinência temática:

É salutar a ampliação dos serviços, mas é necessária a conexão temática. Conforme previsto no Provimento 66 da Corregedoria Nacional de Justiça, que define que as serventias de registro civil das pessoas naturais do Brasil poderão, mediante convênio, credenciamento ou matrícula com órgãos públicos, prestar serviços públicos relacionados à identificação dos cidadãos, visando auxiliar a emissão de documentos pelos órgãos (BRASIL, 2019).

O alicerce sobre o qual se sustenta a norma, sem dúvidas, é a confiança refletida na segurança jurídica oferecida pelos cartórios. Outra vantagem do serviço extrajudicial é a sua capilaridade. Ilustrativamente, destacamos que apenas as serventias de registro civil somam o expressivo número de 13.627 no país, quantidade suficiente para alcançar todos os municípios do Brasil. Como exemplo, a Empresa Brasileira de Correios e Telégrafos possui 6.300 agências no território nacional (dados de 2018). Já o Banco do Brasil conta com 3.692 agências (final de 2019), concentradas nas cidades maiores.

Nesse ponto, é importante tecer comentários mais detidos sobre aquela que é uma das mais importantes especialidades extrajudiciais: o registro civil das pessoas naturais. Os registradores civis são profissionais do direito, dotados de fé pública pelo Estado e fiscalizados pelo Poder Judiciário, cuja remuneração obedece a uma tabela de emolumentos fixada por lei estadual, que são repassados ao Estado em percentuais que em média somam 50\% do valor. É importante notar que os oficiais de registro são civilmente responsáveis por todos os atos praticados no exercício da função, independentemente da prática ter sido pessoal ou por preposto.

Vale lembrar também o forte caráter social dessa especialidade. Como é de amplo conhecimento, $100 \%$ dos registros de nascimento e óbito são gratuitos para todos, incluída a primeira certidão respectiva, nos termos da Lei n. 6.015/1973: “Art. 30. Não serão cobrados emolumentos pelo registro civil de nascimento e pelo assento de óbito, bem como pela primeira certidão respectiva" (BRASIL, 1997). E, desde a entrada em vigor, em 1998, já foram praticados mais de 160 milhões de atos gratuitos. Em relação ao casamento civil, 70\% são realizados gratuitamente para as pessoas pobres.

Outro procedimento que foi desjudicializado com grande êxito foi o reconhecimento de paternidade. Desde 2012, com o provimento n. 16 do CNJ, o reconhecimento tornou-se muito mais simples e célere, realizado diretamente em cartório. Para tanto, basta o comparecimento do genitor à serventia para declarar o reconhecimento com a anuência da mãe ou do filho maior. Todo procedimento ocorre independentemente da manifestação do Ministério Público ou do Poder Judiciário.

O bom desempenho dessas atribuições colocou o cartório como a instituição mais 
confiável do país, segundo a pesquisa "confiança nas instituições" realizada pelo Datafolha, em 2015, nas cidades de Brasília, São Paulo, Rio de Janeiro, Curitiba e Belo Horizonte. Foram 1.045 pessoas abordadas na saída de 97 cartórios. Os inquiridos apontaram as serventias cartoriais como a instituição mais confiável do país, entre todas as instituições públicas e privadas (DATAFOLHA..., 2017).

A pesquisa consistiu em atribuição de uma nota de 0 a 10 - os cartórios alcançado uma média de 7,6. 77\% dos entrevistados ainda se manifestaram contrários a mudanças no sistema atual. O Datafolha também divulgou o perfil do usuário: 55\% têm curso superior, com renda acima de 5 salários-mínimos e 57\% estavam na serventia para uso próprio. As especialidades mais utilizadas foram o serviço de notas (44\%) seguida do registro civil (39\%). Os entrevistados foram, em média, 18 vezes ao cartório nos últimos 12 meses (DATAFOLHA..., 2017).

Convém destacar ainda que a atual estrutura do registro civil contribuiu para que o índice de sub registro no Brasil seja de apenas 1\%, superando a meta estipulada pela ONU, que é de 5\%. Esse feito é fundamental pois o registro do indivíduo representa o seu nascimento como cidadão perante o Estado e a comunidade. E, sem a certidão de nascimento, não é possível obter nenhum outro documento de identificação.

Cita-se ainda uma importante conquista da atividade que é a Central de Informações do Registro Civil, um repositório de dados de nascimento, casamentos e óbitos, incluindo a possibilidade de busca de dados de falecimentos de pessoas não identificadas. A Central é mantida pela Associação dos Registradores de Pessoas Naturais do Brasil (ARPEN Brasil). Essas informações são vitais para o conhecimento da situação do país, possibilitando e subsidiando o implemento de uma série de políticas públicas.

A Central do Registro Civil já conta com mais de 720 milhões de atos em sua base de informações. Graças a um convênio com a Receita Federal do Brasil, os cartórios já emitiram mais 9 milhões de CPFs, gerados por ocasião do registro de nascimento. Por meio de sua plataforma, é possível que qualquer pessoa solicite a certidão de nascimento, casamento ou óbito, podendo optar por retirar a certidão no cartório mais próximo ou recebê-la em casa.

Outra atribuição relativamente recente dos cartórios é a possibilidade deles realizarem o apostilamento de documentos para a produção de efeitos no exterior. Trata-se do ato pelo qual certifica-se a autenticidade de documentos expedidos pelos 112 países signatários da Convenção de Haia (Decreto n. 8.660/2016), permitindo atestar sua origem, selo, assinatura e cargo do agente público. Assim, basta ao interessado levar o documento que desejar validar para uso no exterior a um tabelionato de notas para que a aposição da apostila (formulário fixado no verso do documento) seja realizada no documento original, ao custo de uma procuração sem valor econômico. Dessa forma, fica dispensada a apresentação do documento em consulados onde os procedimentos de legalização de documentos são consideravelmente mais custosos e demorados.

A seguir será analisada a possibilidade de os cartórios oferecerem serviço de mediação e de conciliação, nos termos da norma editada pelo Conselho Nacional de Justiça em 2018. 


\section{MEDIAÇÃO NOS CARTÓRIOS NO BRASIL}

Pelo exposto acima, não se estranha que as serventias extrajudiciais tenham recebido formalmente autorização para realizar mediações. Aliás, há uma vocação natural dessas instituições para a prática de atos consensuais, nos quais está presente o interesse na composição. Exemplos disso são a realização pelas serventias de separações, divórcios, inventários e usucapiões, desde que figurem como partes interessadas, pessoas maiores, capazes e concordes.

Nessa linha, o Conselho Nacional de Justiça editou uma norma administrativa autorizando expressamente a prática dos procedimentos de conciliação e mediação pelos serviços notariais e de registro. Em março de 2018, foi publicado o Provimento n. 67, que determinou aos Núcleos Permanentes de Métodos Consensuais de Solução de Conflitos (NEPEMEC) e às Corregedoriasgerais de justiça a incumbência de fixarem o processo de autorização dos serviços notariais e registrais para a prática de conciliação e mediação.

A atribuição é facultativa aos cartórios, que devem solicitar autorização para prestar o serviço, que ficará sob a fiscalização da respectiva corregedoria geral da justiça bem como do juiz responsável pelo Centro Judiciário de Solução de Conflitos e Cidadania da comarca.

O titular da serventia e os escreventes por ele designados para realizar as mediações (limitado ao máximo de 5), deverão ser formados em cursos para o desempenho da função, oferecidos pelas escolas judiciais de formação ou por associações credenciadas e supervisionadas pelo Poder Judiciário. A preocupação com a formação não parou por aí. Todos os mediadores devem frequentar cursos de aperfeiçoamento a cada dois anos para continuar atuando.

Quanto ao procedimento, as partes interessadas na composição do litígio devem formular um requerimento escrito a uma serventia extrajudicial de qualquer especialidade. O pedido pode ser feito inclusive via formulário padrão disponibilizado pelo tabelião. O cartório deve ter um espaço reservado onde possam ser realizadas as audiências de mediação e de conciliação de maneira a resguardar a privacidade das partes e a confidencialidade do procedimento. O controle dos pedidos de mediação deve ser feito por meio de livro protocolo. Igualmente será aberto um livro próprio para lavratura dos termos de audiência de conciliação e de mediação.

Os cartórios ainda possuem poder para promoverem medidas de incentivo à negociação e à quitação de dívidas protestadas. Trata-se de procedimento previsto no Provimento n. 72/2018 do Conselho Nacional de Justiça, que autoriza o tabelião do protesto de letras e títulos do Brasil a intermediar negociações entre credores e devedores de títulos protestados. Para tanto, deve haver requerimento do credor ou do devedor para a atuação do cartório. A partir daí, a serventia de protesto poderá promover avisos, notificações e poderá receber os valores em condições especiais de abatimento e parcelamento.

\section{CONCLUSÃO}


O crescimento dos meios extrajudiciais de solução de controvérsias representa um inegável avanço. Sobretudo, ao considerar-se que já há alguns anos o Poder Judiciário tem mostrado dificuldades de se desincumbir a contento do grande número de demandas que lhe são propostas diariamente. De fato, o grande volume de litígios judicializados inviabiliza soluções personalizadas, céleres e capazes de alcançar a pacificação efetiva do caso concreto.

Nesse contexto, destaca-se a mediação como uma via adequada para muitos tipos de litígios, nos quais haja possibilidade do diálogo. Como vantagem, este método oferece soluções construídas ativamente pelas partes envolvidas segundo suas necessidades, pretensões e possibilidades. Ademais, por regra, a mediação tende a ser mais célere, poupando os envolvidos do desgaste de um processo judicial, por vezes, mais custoso e longo.

Desta feita, é natural que os métodos extrajudiciais, especialmente a mediação, continuem crescendo e sendo incentivados por entidades públicas e privadas. Especialmente no que tange à mediação notarial, foi salutar a regulamentação da questão. Isso porque o tabelião é, em muitas cidades, o único braço jurídico do Estado. Ele é o profissional do direito que conhece bem a localidade, os costumes e, não raro, atua como uma espécie de consultor jurídico da população, em especial nos municípios menores do interior. Mas, ainda nas capitais e cidades grandes, o tabelião conhece os costumes, a cultura e a sociedade da sua região, podendo auxiliar as partes que o procurem na obtenção de acordos que ultrapassem a superfície meramente formal, e possibilitem a satisfação dos interesses subjacentes dos envolvidos.

Ademais, para além da capacidade jurídica e intelectual, o profissional do extrajudicial, terá naturalmente condições mais favoráveis para mediar os conflitos de sua localidade. Ainda, pelas razões acima, é razoável supor que ele terá maior familiaridade aos problemas de sua região e, consequentemente, maior sensibilidade no trato dos conflitos daí decorrentes.

Convém destacar ainda que a mediação notarial tem o benefício de contar com a interveniência de um profissional dotado de fé pública pelo Estado. A própria formalização do procedimento, bem como do termo de acordo gozam da segurança notarial, sendo perpetuados nos livros e nos arquivos do cartório.

Assim, o notário, como a sua isenção e com confiança nele depositada pelo Estado e pela sociedade certamente goza das armas necessárias para obter um bom desempenho da mediação, podendo oferecer às partes segurança e imparcialidade para a celebração de um acordo equilibrado à luz da lei e do direito, com o escopo na pacificação social.

\section{REFERÊNCIAS}

ADR NOTARIATO. Roma, [2020]. Disponível em: https://www.adrnotariato.org/. Acesso em: 2 jun. 2020.

ALTALEX. Mediazione civile: il testo aggiornato del D.Lgs. 28/2010: Decreto legislativo, 
04/03/2010 n 28, G.U. 05/03/2010. Milano: Altalex, 2020. Disponível em: https://www. altalex.com/documents/codici-altalex/2013/11/04/mediazione-civile-il-testo-aggiornato-del-dlgs-28-2010. Acesso em: 1 jun. 2020.

BANCO do Brasil fecha 409 agências e reduz quadro em 3,7 mil funcionários. Pequenas Empresas e Grandes Negócios, [São Paulo], 13 fev. 2020. Disponível em: https://revistapegn. globo.com/Noticias/noticia/2020/02/banco-do-brasil-fecha-409-agencias-e-reduz-quadro-em-37mil-funcionarios.html. Acesso em: 1 jun. 2020.

BRASIL. Lei $\mathbf{n}^{\mathbf{0}}$ 8.935, de 18 de Novembro de 1994. Regulamenta o art. 236 da Constituição Federal, dispondo sobre serviços notariais e de registro. (Lei dos cartórios). Brasília: Presidência da República, 1994.

BRASIL. Lei $\mathbf{n}^{\mathbf{0}}$ 9.534, de 10 de Dezembro de 1997. Dá nova redação ao art. 30 da Lei no 6.015, de 31 de dezembro de 1973, que dispõe sobre os registros públicos; acrescenta inciso ao art. $1^{\circ}$ da Lei $\mathrm{n}^{\circ} 9.265$, de 12 de fevereiro de 1996, que trata da gratuidade dos atos necessários ao exercício da cidadania; e altera os arts. 30 e 45 da Lei $n^{\circ} 8.935$, de 18 de novembro de 1994, que dispõe sobre os serviços notariais e de registro. Brasília: Presidência da República, 1997.

BRASIL. Supremo Tribunal Federal (2. Turma). Ação direta de inconstitucionalidade (med. liminar) - 5855. Trata-se de ação direta proposta pelo Partido Republicano Brasileiro, PRB, em face do art. 29, $\S \S 3^{\circ}$ e $4^{\circ}$, da Lei Federal 6.015/1973, Lei de Registros Públicos, com a redação dada pela Lei Federal 13.484/2017, dispositivos que facultam aos ofícios de registro civil das pessoas naturais de todo país a prestação de serviços remunerados mediante a celebração de convênios, credenciamento ou matrícula com órgãos públicos e entidades de outra naturezaRecorrente: Partido Republicano Brasileiro - PRB. Recorrido: Presidente Da República, Congresso Nacional. Relator: Min. Alexandre de Moraes, 25 de setembro de 2019. Disponível em: http://www.stf.jus.br/portal/peticaoInicial/verPeticaoInicial. asp? base $=$ ADI\&documento $=\& s 1=5855 \&$ numProcesso $=5855$. Acesso em: 1 nov. 2019 .

DATAFOLHA aponta cartórios como a instituição mais confiável do Brasil. Registro Civil, [São Paulo], 13 jul. 2017. Disponível em: https://blog.registrocivil.org.br/2017/07/13/datafolhaaponta-cartorios-como-a-instituicao-mais-confiavel-do-brasil/. Acesso em: 30 maio 2020.

ESTRASBURGO. Parlamento Europeu. P8_TA(2017)0321. Resolução do Parlamento Europeu, de 12 de setembro de 2017, sobre a aplicação da Diretiva 2008/52/CE do Parlamento Europeu e do Conselho, de 21 de maio de 2008, sobre certos aspetos da mediação em matéria civil e comercial 2017. Estrasburgo: PE, 2027. Disponível em: https://www.europarl.europa.eu/doceo/ document/TA-8-2017-0321_PT.html?redirect. Acesso em: 20 maio 2020.

ESTRASBURGO. Parlamento Europeu. Conselho da União Europeia. Directiva 2008/52/ CE do Parlamento Europeu e do Conselho relativa a certos aspectos da mediação em matéria civil e comercial. Jornal Oficial da União Européia, Estrasburgo, 24 maio 2008. Directivas. Disponível em: https://eur-lex.europa.eu/LexUriServ/LexUriServ. do?uri=OJ:L:2008:136:0003:0008:PT:PDF. Acesso em: 2 jun. 2020.

FRANCAVIGLIA, Rosa. Come tutelarsi nellaa mediazione immobiliare. Santarcanjo di Romagna: Maggioli Editore, 2009.

ITÁLIA. Ministero Dello Sviluppo Economico. Legge 29 dicembre 1993, n. 580. 
Riordinamento delle camere di commercio, industria, artigianato e agricoltura. Roma: MISE, 1993. Disponível em: https://www.mise.gov.it/images/stories/commercio_internazionale/ legge_580_93/Legge_580_1993.pdf. Acesso em: 10 maio 2020.

JOÃO PAULO II, Papa. Discurso do Papa João Paulo II durante o conferimento do Prêmio Internacional "Carlos Magno" da Cidade de Aquisgrano. Vaticano: Libreria Editrice Vaticana, 2004. Disponível em: http://www.vatican.va/content/john-paul-ii/pt/speeches/2004/ march/documents/hf_jp-ii_spe_20040324_premio-carlo-magno.html. Acesso em: 25 maio 2020.

LA STORIA del Notariato. Milano: The Italian Notaries, 2005. Disponível em: https://www. notaio-busani.it/it-IT/notaio-storia.aspx. Acesso em: 20 maio 2020.

MATTUCCI, Giovanni. Mediazione e giudici in Italia. Mondo ADR, Roma, 9 mar. 2019.

PORTAL DA TRANSPARÊNCIA. Portal da Transparência do Registro Civil. 2020.

Disponível em: https://transparencia.registrocivil.org.br/inicio. Acesso em: 25 maio 2020.

SANTOS, Reinaldo Velloso dos. Apontamentos sobre o protesto notarial. 2012. Dissertação (Mestrado em Direito) - Faculdade de Direito da Universidade de São Paulo, São Paulo, 2012.

SARRACENO, Massimo. L'attività notarile a valle del procedimento di mediazione alla luce dell'art. 83, comma 20-bis, D.L. 17 marzo 2020, n.18. Feder Notizie, Lombardia, 20 mag. 2020. Disponível em: https://www.federnotizie.it/lattivita-notarile-a-valle-del-procedimentodi-mediazione-alla-luce-dellart-83-comma-20-bis-d-1-17-marzo-2020-n-18/. Acesso em: 5 jun. 2020 .

URSO, Elena. La mediazione familiare: modeli, principi, objetivi. Firenze: Firenze University Press, 2012.

VERDÉLIO, Andreia. Correios fecham 41 agências a partir de hoje. Agência Brasil, Brasília, 16 out. 2018. Disponível em: https://agenciabrasil.ebc.com.br/geral/noticia/2018-10/correiosfecham-41-agencias-partir-de-hoje. Acesso em: 20 maio 2020.

VIGORITI, Vicenzo. Europa e Mediazione: problemi e soluzioni. Revista de Direitos e Garantias Fundamentais, Vitória, n. 5, jan./ jun. 2009.

Como citar: GARANI, Joao; DENARDI, Eveline. Mediação em cartórios na Itália e no Brasil. Scientia luris, Londrina, v. 25, n. 3, p. 91-108, nov. 2021. DOI 10.5433/21788189.2021v25n3p92. ISSN: 2178-8189.

Recebido em 2021-09-09

Aprovado em 2021-09-18 